\title{
Prospective and Randomized Evaluation of ChronOS and Bio-Oss in Human Maxillary Sinuses: Histomorphometric and Immunohistochemical Assignment for Runx 2, Vascular Endothelial Growth Factor, and Osteocalcin
}

\author{
João Paulo Bonardi, DDS, MSc, ${ }^{*}$ Rodrigo dos Santos Pereira, DDS, MSc, PhD, $\dagger$ \\ Fernanda Brasil Daura Jorge Boos Lima, DDS, MSc, PbD, \\ Leonardo Perez Faverani, DDS, MSc, PbD, $\S$ Geraldo Luiz Griza, DDS, MSc, PbD, /| \\ Roberta Okamoto, DDS, MSc, PhD, T and Eduardo Hochuli-Vieira, DDS, MSc, PhD\#
}

Purpose: The aim of this study was to compare ChronOS ( $\beta$-tricalcium phosphate), Bio-Oss, and their addition to an autogenous bone graft in a 1:1 ratio in human maxillary sinus bone augmentation.

\begin{abstract}
Materials and Methods: Thirty maxillary sinuses were divided in 5 groups: group 1 included 6 maxillary sinuses grafted with autogenous bone graft alone; group 2 included 6 maxillary sinuses grafted with ChronOS; group 3 included 6 maxillary sinuses grafted with ChronOS and autogenous bone graft in a 1:1 ratio; group 4 included 6 maxillary sinuses grafted with Bio-Oss; and group 5 included 6 maxillary sinuses grafted with Bio-Oss and autogenous bone graft in a 1:1 ratio. The number of samples for each group was determined by the statistical power test.
\end{abstract}

Results: The median areas of new bone formation in groups 1, 2, 3, 4, and 5 were 121,917.0, 83,787.0, $99,295.0,65,717.0$, and $56,230.0 \mu \mathrm{m}^{2}$, respectively. Statistically significant differences were found between groups 3 and 5 , groups 1 and 4 , and groups 1 and $5(P<.05)$. The median areas of remaining biomaterial were 2,900.5, 5,291.0, 2,662.0, 56,258.5, and 64,753.5 $\mu^{2}$ in groups $1,2,3,4$ and 5, respectively. Statistically significant differences occurred between groups 1 and 5 , groups 3 and 5 , and groups 2 and $5(P<.05)$. Areas of connective tissue were $67,829.0 \pm 22,984.6 \mu \mathrm{m}^{2}$ in group $1,97,445.9 \pm 18,983.3 \mu \mathrm{m}^{2}$ in group 2 , $88,256.0 \pm 21,820.5 \mu \mathrm{m}^{2}$ in group 3, 65,501.8 $\pm 6,297.6$ in group 4 , and 70,203.2 $\pm 13,421.3 \mu \mathrm{m}^{2}$ in group 5 .

Received from the Universidade Estadual Paulista "Júlio de Mesquita Filho", São Paulo, SP, Brazil

${ }^{*} \mathrm{PhD}$ Student, Surgery and Integrated Clinic Department, Universidade Estadual Paulista "Júlio de Mesquita Filho", São Paulo, SP, Brazil.

†Oral and Maxillofacial Surgeon, Surgery and Integrated Clinic Department, Universidade Estadual Paulista "Júlio de Mesquita Filho", São Paulo, SP, Brazil.

‡Oral and Maxillofacial Surgeon, Universidade Federal de Minas Gerais, Department of Clinics, Pathology and Surgery, Pampulha, Belo Horizonte - MG, Brazil.

$\S$ Oral and Maxillofacial Surgery Professor, Surgery and Integrated Clinic Department, Universidade Estadual Paulista "Júlio de Mesquita Filho”, São Paulo, SP, Brazil.

$\|$ Oral and Maxillofacial Surgeon, Surgery and Integrated Clinic Department, Universidade Estadual Paulista "Júlio de Mesquita Filho”, São Paulo, SP, Brazil.
TAnatomy Professor, Surgery and Integrated Clinic Department, Universidade Estadual Paulista "Júlio de Mesquita Filho", São Paulo, SP, Brazil.

\#Oral and Maxillofacial Surgery Professor, Surgery and Integrated Clinic Department, Universidade Estadual Paulista "Júlio de Mesquita Filho”, São Paulo, SP, Brazil.

This study was supported by the CAPES and FAPESP (process numbers 2012/08455-4 and 2012/10028-7).

Conflict of Interest Disclosures: None of the authors have a relevant financial relationship(s) with a commercial interest.

Address correspondence and reprint requests to Dr Pereira: Zeferino Street 243, Mesquita, Rio de Janeiro 26551-081, Brazil; e-mail: dr.pereira@live.com

Received May 152017

Accepted September 252017

(C) 2017 American Association of Oral and Maxillofacial Surgeons

0278-2391/17/31244-2 
Conclusions: ChronOS combined with autogenous bone graft presented a behavior similar to that of autogenous bone graft alone. However, the groups treated with Bio-Oss showed immuno-labeling results indicating maturation of grafted bone.

(C) 2017 American Association of Oral and Maxillofacial Surgeons

J Oral Maxillofac Surg 76:325-335, 2018

Edentulism is a general condition that involves the elderly population, regardless of gender. ${ }^{1,2}$ Tooth loss leads to bone atrophy in the alveolar process. However, in the posterior maxillary region, it is more aggravating because of maxillary sinus pneumatization., ${ }^{2,3}$ This condition makes dental implant placement for prosthetic rehabilitation impossible; nevertheless, surgical maneuvers can increase bone height, making this treatment possible through the lateral wall approach to the maxillary sinus developed by Boyne and James. ${ }^{4,5}$

The autogenous bone graft remains the gold standard to reconstruct areas with bone defects because of its osteogenic, osteoinduction, and osteoconduction properties. ${ }^{6,7}$ However, another surgical site is necessary for harvesting, and depending on the amount of bone graft required, there is a greater risk of morbidity to the patient. ${ }^{8,9}$ Therefore, biomaterials, such as xenografts, alloplastic grafts, and allogenic grafts, have been developed to recover maxillary sinus bone height, with promising outcomes. ${ }^{10-12}$

One example of an osteoconductive biomaterial is $\beta$ tricalcium phosphate ( $\beta$-TCP). It is a microporous bone substitute with fast resorption and good results have been reported in literature; however, its predictability is unknown. ${ }^{13-17}$ Chronos (DePuy Synthes, Paoli, CA) is a $\beta$-TCP with a homogeneous porous structure, which improves the surface area, hastens graft resorption, and facilitates biological fluid circulation and cell attachment, leading to vascular net formation and bone growth. ${ }^{18}$

Another biomaterial with structural characteristics similar to bone marrow is Bio-Oss (Geistlich Pharma, Wolhusen, Switzerland). ${ }^{19}$ It is a xenograft whose morphology is similar to that of $\beta$-TCP, permitting the proliferation of blood vessels and bone cell migration through the interconnecting porous system. ${ }^{20}$ Nevertheless, studies comparing the inorganic bovine graft with $\beta$-TCP are scarce in the literature. ${ }^{21}$

To understand the osteoblastic differentiation during the bone graft healing phase, it is necessary to evaluate the mediator of this process. Runt-related transcription factor 2 (Runx2) is responsible for regulating the differentiation of pluripotent mesenchymal cells in the initial period of bone repair. ${ }^{22}$ In addition, it regulates endochondral bone formation and vascular invasion in cartilage. ${ }^{23}$ Vascular endothelial growth factor (VEGF) is a growth factor responsible for the migration and proliferation of endothelial cells during the period of bone healing, allowing the vascular formation to conduct nutrients to the region of the bone graft. ${ }^{24-30}$ Osteocalcin is a protein associated with bone calcification and its expression refers to bone maturation. ${ }^{31,32}$

The aim of this study was to compare new bone formation using ChronOS and Bio-Oss alone and added to autogenous bone graft in a 1:1 ratio with autogenous bone graft alone through histometry and immunohistochemical assessment of Runx2, VEGF, and osteocalcin after 6 months of bone healing of maxillary sinus augmentation to permit dental implant placement.

The null hypothesis (H0) of this study was there would be no difference in new bone formation among the bone substitutes evaluated after 6 months of bone healing. The alternative hypothesis (H1) was there would be a difference in new bone formation among the bone substitutes evaluated after 6 months of bone healing.

\section{Materials and Methods}

This prospective clinical study was performed at the Araçatuba Dental School of the Universidade Estadual Paulista (São Paulo, SP, Brazil), was approved by the ethical committee (protocol number 47711015.4.0000.5420), and followed the Declaration of Helsinki. All participants signed an informed consent agreement. The inclusion criteria were patients with pristine maxillary sinus bone height less than $5 \mathrm{~mm}$ who required bone grafting to allow dental implant placement. Patients were excluded if they had uncontrolled systemic diseases, smoked, had periodontitis, had maxillary sinus pathologies, or received radiation treatment to the head or neck. Cone-beam computed tomograms were obtained previously to evaluate all maxillary sinuses. Thirty patients with unilateral maxillary sinuses that needed grafting were invited to participate in this study and were divided into 5 groups: 6 were grafted with autogenous bone graft alone (group 1); 6 were grafted with ChronOS alone (group 2); 6 were grafted with ChronOS and autogenous bone graft in a 1:1 ratio (group 3); 6 were grafted with Bio-Oss alone (group 4); and 6 were grafted with Bio-Oss and autogenous bone graft in a 1:1 ratio (group 5). The number of the samples for each group was determined by a statistical power test (http://www.lee.dante.br) based on previous results. ${ }^{33}$ The difference in the average to be detected was 15.1, with a standard deviation of 9.9, a significance level of $5 \%$, and a power test of 


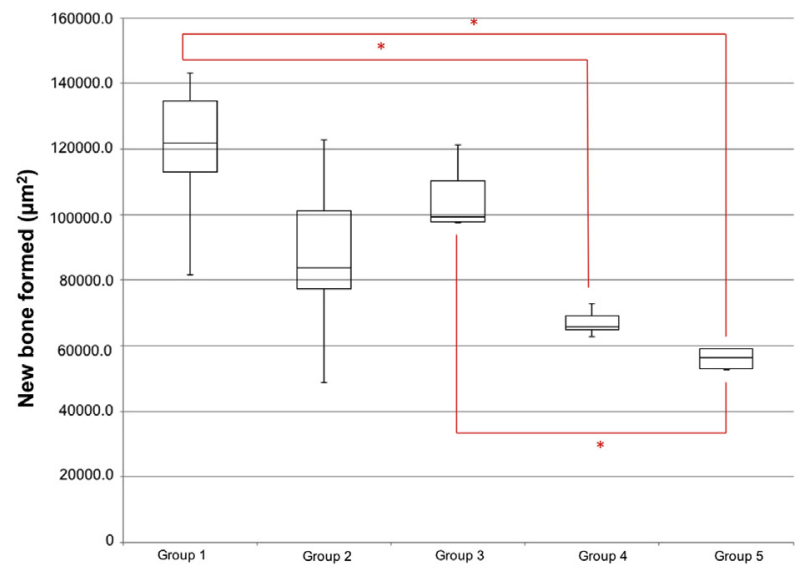

FIGURE 1. Graphic of new bone formed in maxillary sinus bone augmented using the 5 bone substitutes after 6 months of bone healing. ${ }^{*} P<.05$, statistically significant difference.

Bonardi et al. Chronos Versus Bio-OSS in Human Maxillary Sinuses J Oral Maxillofac Surg 2018.

$80 \%$, in a 1-tail hypothesis test. Randomization was performed by drawing lots to decide which patients would be grafted with each material. This was performed by a clinical assistant who was not involved in the surgeries or data evaluation.

All surgical procedures were performed under local anesthesia using 2\% lidocaine with 1:100,000 epinephrine (DFL, Taquara, RJ, Brazil) by a single researcher trained in advance for this work. Cortical autogenous bone graft blocks were removed from the mandibular symphysis or retromolar region and pulverized with a bone crusher (Neodent, Curitiba, PR, Brazil) as reported by Pereira et al. ${ }^{33}$ The maxillary sinus was augmented according to the procedure described by Boyne and James. ${ }^{5}$ During the first week, all patients were administered paracetamol $500 \mathrm{mg}$ (EMS, São Paulo, SP, Brazil) 4 times per day to decrease pain and amoxicillin $500 \mathrm{mg}$ (EMS) 3 times per day to lower the chance of infection.

\section{HISTOMORPHOMETRIC ANALYSIS}

After 6 months of bone healing, biopsy samples were collected at the time of dental implant placement with a 3.0- $\times 15-\mathrm{mm}$ trephine bur (MK Life. Porto Alegre, RS, Brazil) and stored in a $10 \%$ formalin solution $(\mathrm{pH}, 7)$ for 48 hours. The samples were washed in running water for 24 hours and decalcified in ethylenediaminetetra-acetic acid solution for 4 weeks. The solution was changed weekly. Next, samples were embedded in paraffin, sliced to a thickness of $5 \mu \mathrm{m}$, placed on slides, and stained with hematoxylin and eosin. Biopsy samples were evaluated by light microscopy, and images were captured using the attached digital camera (JVC TK1270 Color Video Camera; Victor Company of Japan Ltd, Tokyo, Japan) at $\times 12.5$ magnification. Images were analyzed using the ImageJ 150e (National Institutes of Health, Bethesda, MD) in the original size. Images from 3 areas of the specimens were captured: pristine bone ( $2 \mathrm{~mm}$ above the upper side of the maxillary sinus floor) and intermediate and apical bone ( $2 \mathrm{~mm}$ below the Schneiderian membrane). Areas (square micrometers) of new bone formation, connective tissue, and remaining biomaterial were calculated, and the results of each area were added to represent the total sample. All analyses and data collection were performed by a single researcher trained in advance for this work.

\section{IMMUNOHISTOCHEMICAL ANALYSIS}

Primary polyclonal goat anti-human antibodies targeting VEGF, Runx2, and osteocalcin (Santa Cruz Biotechnology, Santa Cruz, CA; catalog numbers SC1881, SC8566, and SC18319, respectively) were used in immunohistochemical assays. As a secondary antibody, a biotinylated donkey anti-goat antibody (Jackson Immunoresearch Laboratories, West Grove, PA) coupled with avidin (Vector Laboratories, Burlingame, CA) was used for signal amplification, and diaminobenzidine

Table 1. HISTOLOGIC RESULTS FOR NEW BONE FORMATION IN MAXILLARY SINUSES GRAFTED WITH THE BIOMATERIALS EVALUATED

New Bone Formed

\begin{tabular}{lccccc}
\cline { 2 - 6 } Maxillary Sinus & Group 1 $\left(\mu \mathrm{m}^{2}\right)^{*}$ & Group 2 $\left(\mu \mathrm{m}^{2}\right)$ & Group 3 $\left(\mu \mathrm{m}^{2}\right)^{\dagger}$ & Group 4 $\left(\mu \mathrm{m}^{2}\right)^{*}$ & $\mathrm{Group} \mathrm{5}^{*}\left(\mu \mathrm{m}^{2}\right)^{* \dagger}$ \\
\hline 1 & 143,084 & 77,168 & 121,188 & 72,726 & 68,828 \\
2 & 81,778 & 105,154 & 113,479 & 66,545 & 58,979 \\
3 & 136,946 & 122,650 & 61,119 & 64,811 & 39,606 \\
4 & 112,055 & 48,683 & 97,455 & 62,756 & 53,482 \\
5 & 127,609 & 78,272 & 100,152 & 69,943 & 59,210 \\
6 & 116,225 & 89,302 & 98,258 & 64,889 & 52,634 \\
Median & $121,917.0$ & $83,787.0$ & $99,205.0$ & $65,717.0$ & $56,230.0$ \\
\hline
\end{tabular}

${ }^{*} P<.05$, statistically significant difference.

$\dagger P<.05$, statistically significant difference.

Bonardi et al. Chronos Versus Bio-OSS in Human Maxillary Sinuses. J Oral Maxillofac Surg 2018. 


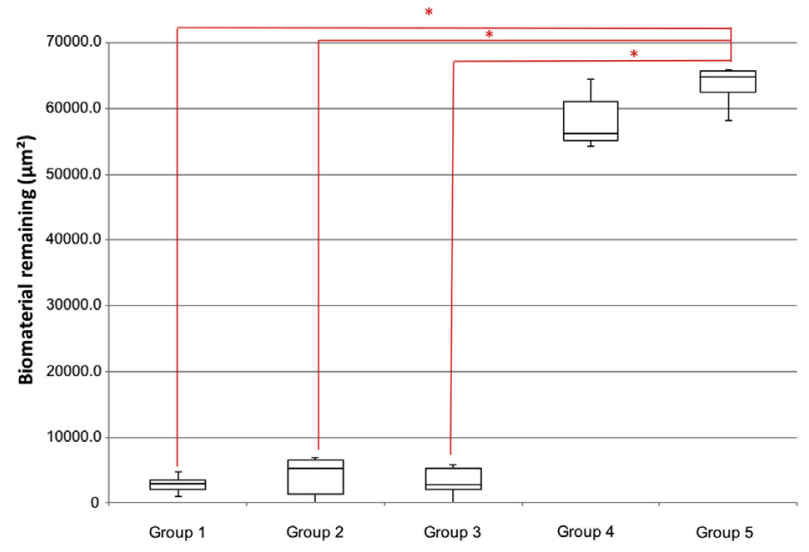

FIGURE 2. Graphic of biomaterials remaining in maxillary sinus bone augmented using the 5 bone substitutes after 6 months of bone healing. ${ }^{*} P<.05$, statistically significant difference.

Bonardi et al. Chronos Versus Bio-OSS in Human Maxillary Sinuses. J Oral Maxillofac Surg 2018.

(Sigma-Aldrich, St Louis, MO) was used as a chromogenic substrate for avidin. Images of the samples were captured using the same method as the histomorphometric evaluation. Data analyses were performed using a single-evaluator semiquantitative approach, with scores of 0 indicating the absence of staining and scores of 1,2 , or 3 indicating low, moderate, or intense staining, respectively, ${ }^{33}$ for each region, and an average of the scores was assigned. All these analyses were performed by a single researcher trained in advance.

\section{STATISTICAL ANALYSIS}

The Shapiro-Wilk test was performed to determine whether the outcomes had a normal distribution. No parametric data were shown for new bone formation and remaining biomaterial. The Kruskal-Wallis test was performed to compare groups, followed by the
Tukey multiple comparison test. For connective tissue formation, the data showed parametric results and the comparison was performed using analysis of variance, followed by the Tukey multiple comparison test (SigmaPlot 12.3; Systat Software, San Jose, CA). An a priori $P$ value less than .05 was used for all tests.

\section{Results}

\section{HISTOMORPHOMETRIC RESULTS}

The median areas of new bone formation were $121,917.0 \mu \mathrm{m}^{2}$ in group $1,83,787.0 \mu \mathrm{m}^{2}$ in group 2 , $99,295.0 \mu \mathrm{m}^{2}$ in group $3,65,717.0 \mu \mathrm{m}^{2}$ in group 4 , and $56,230.0 \mu \mathrm{m}^{2}$ inr group 5. Statistical differences occurred between groups 3 and 5, groups 1 and 4 , and groups 1 and $5(P<.05$; Fig 1 , Table 1$)$. These results contradicted $\mathrm{H} 0$ and validated $\mathrm{H} 1$.

The median areas of the remaining biomaterial were $2,900.5 \mu \mathrm{m}^{2}$ for group $1,5,291.0 \mu \mathrm{m}^{2}$ for group 2 , $2,662.0 \mu \mathrm{m}^{2}$ for group 3, 56,258.5 $\mu \mathrm{m}^{2}$ for group 4 , and $64,753.5 \mu \mathrm{m}^{2}$ for group 5. Statistical differences for remaining biomaterial occurred between groups 1 and 5, groups 3 and 5, and groups 2 and 5 $(P<.05$; Fig 2 , Table 2$)$.

The average areas of connective tissue were $67,829.0 \pm 22,984.6 \mu^{2}$ for group 1, $97,445.9 \pm 18,983.3 \mu \mathrm{m}^{2}$ for group 2, $88,256.0 \pm 21,820.5 \mu^{2}$ for group 3, $65,501.8 \pm 6,297.6$ for group 4, and $70,203.2 \pm 13,421.3 \mu \mathrm{m}^{2}$ for group 5 . Statistically significant differences occurred only between groups 2 and 4 $(P<.05$; Fig 3, Table 3).

Group 1 showed highly cellular connective tissue with the presence of vessels and mature new bone formation with a lamellar organization and osteocytes entrapped within the extracellular matrix (Fig 4). New bone formation in group 2 presented with a lamellar

\section{Table 2. HISTOLOGIC RESULTS FOR BIOMATERIALS REMAINING IN MAXILLARY SINUSES GRAFTED WITH THE BIOMATERIALS EVALUATED}

Remaining Biomaterial

\begin{tabular}{|c|c|c|c|c|c|}
\hline Maxillary Sinus & Group $1\left(\mu \mathrm{m}^{2}\right)^{*}$ & Group $2\left(\mu \mathrm{m}^{2}\right)^{\dagger}$ & Group $3\left(\mu \mathrm{m}^{2}\right)^{\ddagger}$ & Group $4\left(\mu \mathrm{m}^{2}\right)$ & Group $5\left(\mu \mathrm{m}^{2}\right)^{* \dagger \dagger}$ \\
\hline 1 & 4,763 & 6,883 & 143 & 56,320 & 74,893 \\
\hline 2 & 883 & 0 & 10,501 & 64,495 & 65,902 \\
\hline 3 & 1,956 & 0 & 1,966 & 54,225 & 64,865 \\
\hline 4 & 3,435 & 18,707 & 1,942 & 56,197 & 58,209 \\
\hline 5 & 2,366 & 5,188 & 3,358 & 62,580 & 61,825 \\
\hline 6 & 3,457 & 5,394 & 5,847 & 54,759 & 64,642 \\
\hline Median & $2,900.5$ & $5,291.0$ & $2,662.0$ & $56,258.5$ & $64,753.5$ \\
\hline
\end{tabular}

* $P<.05$, statistically significant difference.

$\dagger P<.05$, statistically significant difference.

$\ddagger P<.05$, statistically significant difference.

Bonardi et al. Chronos Versus Bio-OSS in Human Maxillary Sinuses. J Oral Maxillofac Surg 2018. 


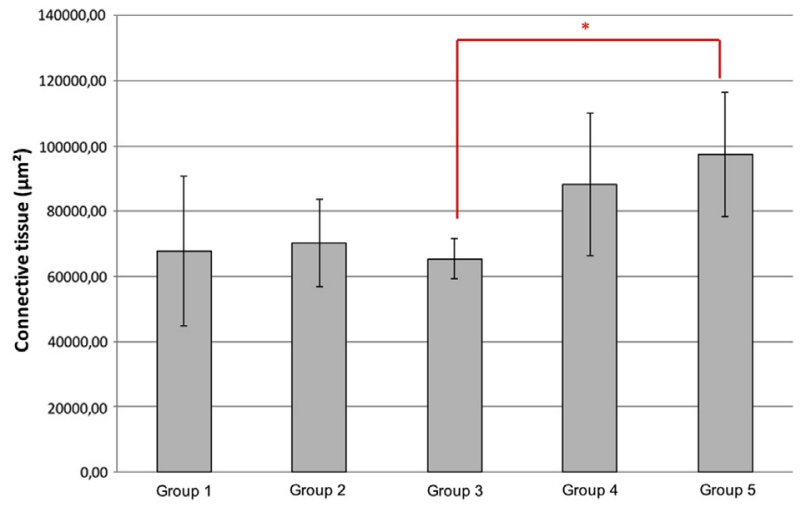

FIGURE 3. Graphic of connective tissue formed in maxillary sinus bone augmented using the 5 bone substitutes after 6 months of bone healing. ${ }^{\star} P<.05$, statistically significant difference.

Bonardi et al. Chronos Versus Bio-OSS in Human Maxillary Sinuses. J Oral Maxillofac Surg 2018.

organization and woven bone areas but with osteocytes in the extracellular matrix. The presence of the remaining biomaterial could be observed being reabsorbed, with new bone formation on the periphery and highly cellular connective tissue (Fig 5). In group 3 , it was possible to observe particles of autogenous bone graft remaining, with empty osteocytes and lacunas and new bone formation on the periphery with lamellar organization (Fig 6). In group 4, a large number of remaining biomaterial particles were observed, with new bone formation on the periphery in intimate contact with the particles (Fig 7). Group 5 was similar to group 4 , but the presence of connective tissue was more prominent (Fig 8).

\section{IMMUNOHISTOCHEMICAL RESULTS}

Immuno-labeling for Runx 2 was low (score, 1) for osteoblastic cells in groups 1, 2, 4, and 5; however, moderate (score, 2) immunostaining was found for

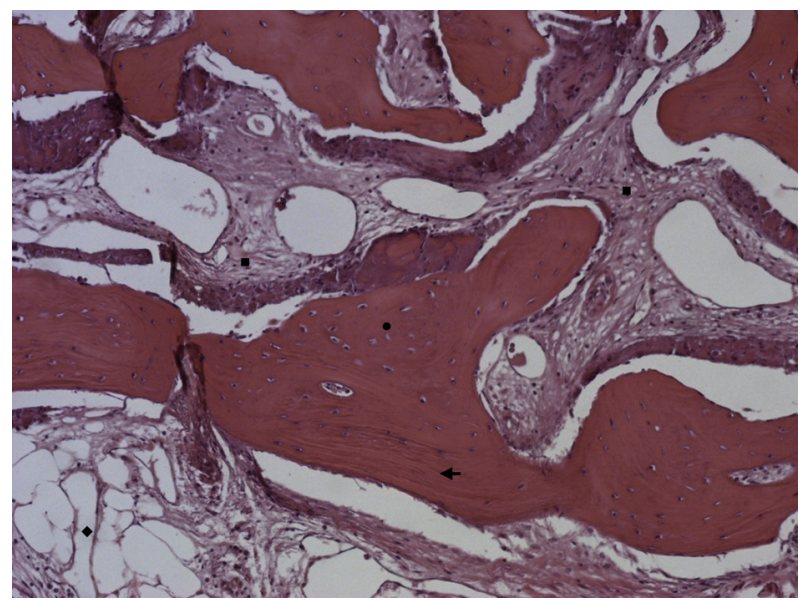

FIGURE 4. Histologic section of group 1 with area of woven bone (circle), connective tissue (square), lamellar bone formation (arrow), and bone marrow (diamond) (hematoxylin and eosin stain; magnification, $\times 12.5)$.

Bonardi et al. Chronos Versus Bio-OSS in Human Maxillary Sinuses. J Oral Maxillofac Surg 2018.

group 3 (Figs 9A-E). For VEGF, groups 1 and 2 showed moderate (score, 2) immuno-labeling, group 5 showed low (score, 1) staining, and groups 3 and 4 showed intense (score, 3) staining (Figs 10A-E). For osteocalcin, intense staining of the bone surface (score, 3) was observed in all groups (Figs 11A-E; Table 4).

\section{Discussion}

Rates of bone graft resorption using $\beta$-TCP alone, $\beta$ TCP and autogenous bone graft (1:1), and autogenous bone graft alone were, respectively, $38.33,43.82$, and $45.75 \%$, as reported by Gorla et al. ${ }^{17}$ In their study, they performed further analysis to evaluate new bone formation by immunohistochemical assessment and compared the materials qualitatively. Dos Santos Pereira et $\mathrm{al}^{34}$ reported more bone formation using

Table 3. HISTOLOGIC RESULTS FOR CONNECTIVE TISSUE FORMED IN MAXILLARY SINUSES GRAFTED WITH THE BIOMATERIALS EVALUATED

Connective Tissue

\begin{tabular}{lccccc}
\cline { 2 - 6 } Maxillary Sinus & Group 1 $\left(\mu \mathrm{m}^{2}\right)$ & Group 2 $\left(\mu \mathrm{m}^{2}\right)$ & Group 3 $\left(\mu \mathrm{m}^{2}\right)^{*}$ & Group 4 $\left(\mu \mathrm{m}^{2}\right)$ & $\mathrm{Group}^{2}\left(\mu \mathrm{m}^{2}\right)^{*}$ \\
\hline 1 & 42,317 & 105,744 & 69,804 & 61,946 & 46,995 \\
2 & 107,824 & 85,928 & 66,595 & 59,535 & 65,925 \\
3 & 51,169 & 67,835 & 127,724 & 71,170 & 86,200 \\
4 & 74,812 & 122,633 & 91,409 & 71,622 & 78,980 \\
5 & 60,272 & 106,740 & 87,319 & 58,128 & 69,672 \\
6 & 70,580 & 95,795 & 86,685 & 70,610 & 73,447 \\
Mean & $67,829.0$ & $97,445.9$ & $88,256.0$ & $65,501.8$ & $70,203.2$ \\
SD & $22,984.6$ & $18,983.3$ & $21,820.5$ & $6,297.6$ & $13,421.3$ \\
\hline
\end{tabular}

Abbreviation: SD, standard deviation.

${ }^{*} P<.05$, statistically significant difference.

Bonardi et al. Chronos Versus Bio-OSS in Human Maxillary Sinuses. J Oral Maxillofac Surg 2018. 


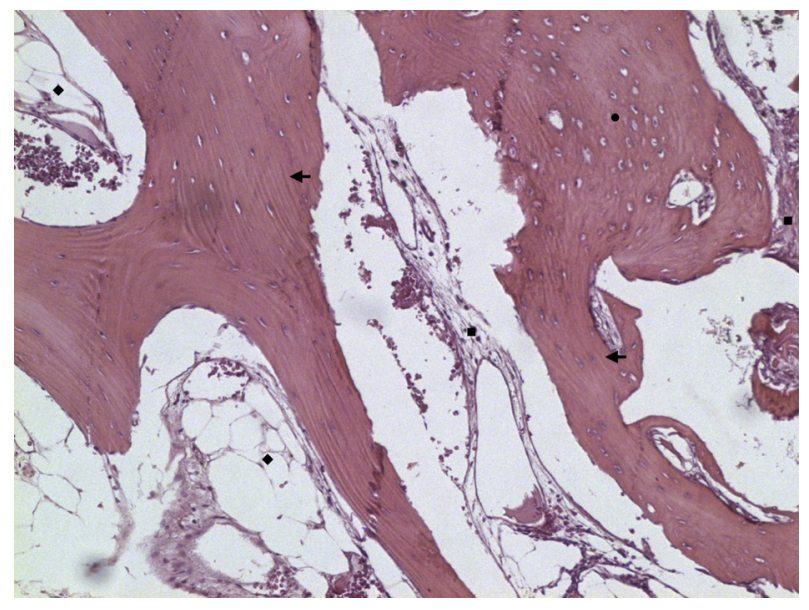

FIGURE 5. Histologic section of group 2 with area of woven bone (circle), connective tissue (square), lamellar bone formation (arrow), and bone marrow (diamond) (hematoxylin and eosin stain; magnification, $\times 12.5)$.

Bonardi et al. Chronos Versus Bio-OSS in Human Maxillary Sinuses. J Oral Maxillofac Surg 2018.

an autogenous bone graft than its combination with $\beta$ TCP in a 1:1 ratio.

The resorption of $\beta$-TCP after maxillary sinus bone augmentation was similar to that of autogenous bone graft. This similarity is an advantage compared with other bone substitutes because its resorption rate indicates the need for overcorrection to obtain the expected outcome. ${ }^{17}$ New bone formation using pure $\beta$-TCP as a bone substitute has similar results to those using autogenous bone graft; however, when the mixture is in a $1: 1$ proportion, a delay of bone maturation is observed. ${ }^{34}$

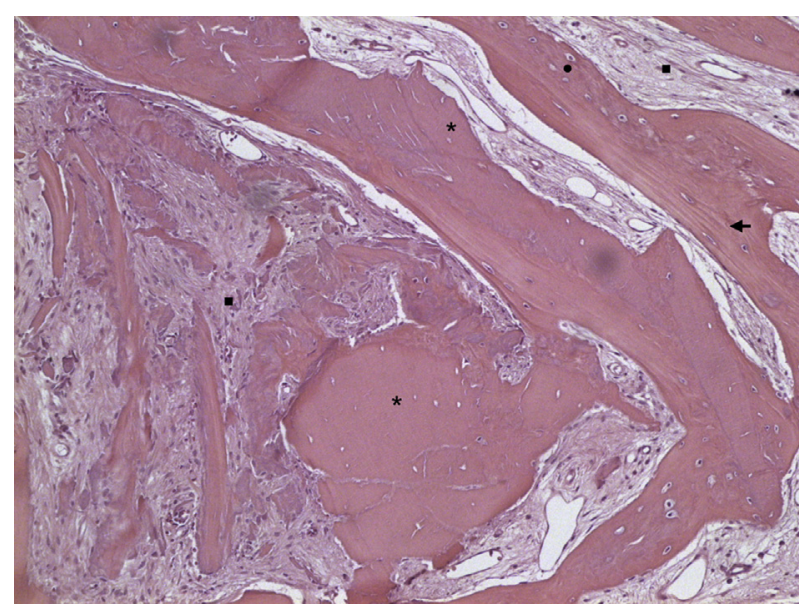

FIGURE 6. Histologic section of group 3 with area of woven bone (circle), connective tissue (square), lamellar bone formation (arrow), and remaining autogenous bone graft (asterisk) (hematoxylin and eosin stain; magnification, $\times 12.5$ ).

Bonardi et al. Chronos Versus Bio-OSS in Human Maxillary Sinuses. J Oral Maxillofac Surg 2018.

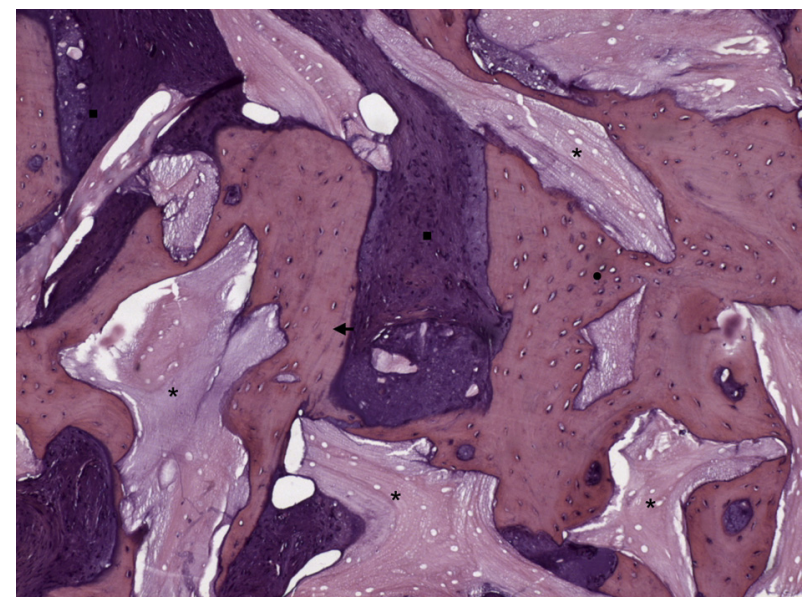

FIGURE 7. Histologic section of group 4 with area of woven bone (circle), connective tissue (square), lamellar bone formation (arrow), and remaining Bio-Oss particle (asterisk) (hematoxylin and eosin stain; magnification, $\times 12.5$ ).

Bonardi et al. Chronos Versus Bio-OSS in Human Maxillary Sinuses. J Oral Maxillofac Surg 2018.

Jensen et $\mathrm{al}^{35}$ reported no difference in new bone formation in maxillary sinus bone augmentation using Bio-Oss or its addition to autogenous bone graft in different proportions, and bone formation tends to improve in the long-term. In the present study, new bone formed using Bio-Oss was similar to that of its mixture with autogenous bone graft in a 1:1 ratio after 6 months of bone augmentation. However, bone formation occurred in a smaller area of the 2 groups compared with the autogenous bone graft.

Shirmohammadi et $\mathrm{al}^{36}$ reported $33.13 \%$ of Bio-Oss particles remained in the maxillary sinus after

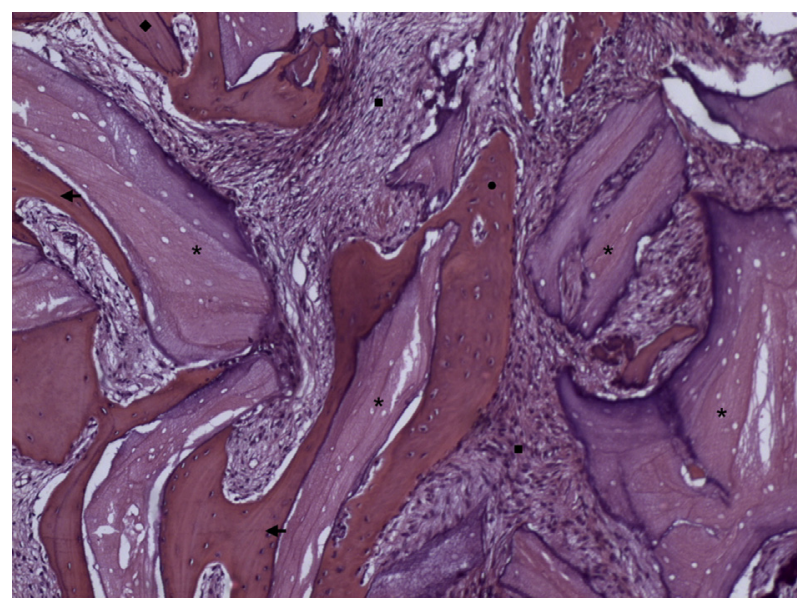

FIGURE 8. Histologic section of group 5 with area of woven bone (circle), connective tissue (square), lamellar bone formation (arrow), remaining Bio-Oss particle (asterisk), and remaining autogenous bone particle (diamond) (hematoxylin and eosin stain; magnification, $\times 12.5)$.

Bonardi et al. Chronos Versus Bio-OSS in Human Maxillary Sinuses. J Oral Maxillofac Surg 2018. 

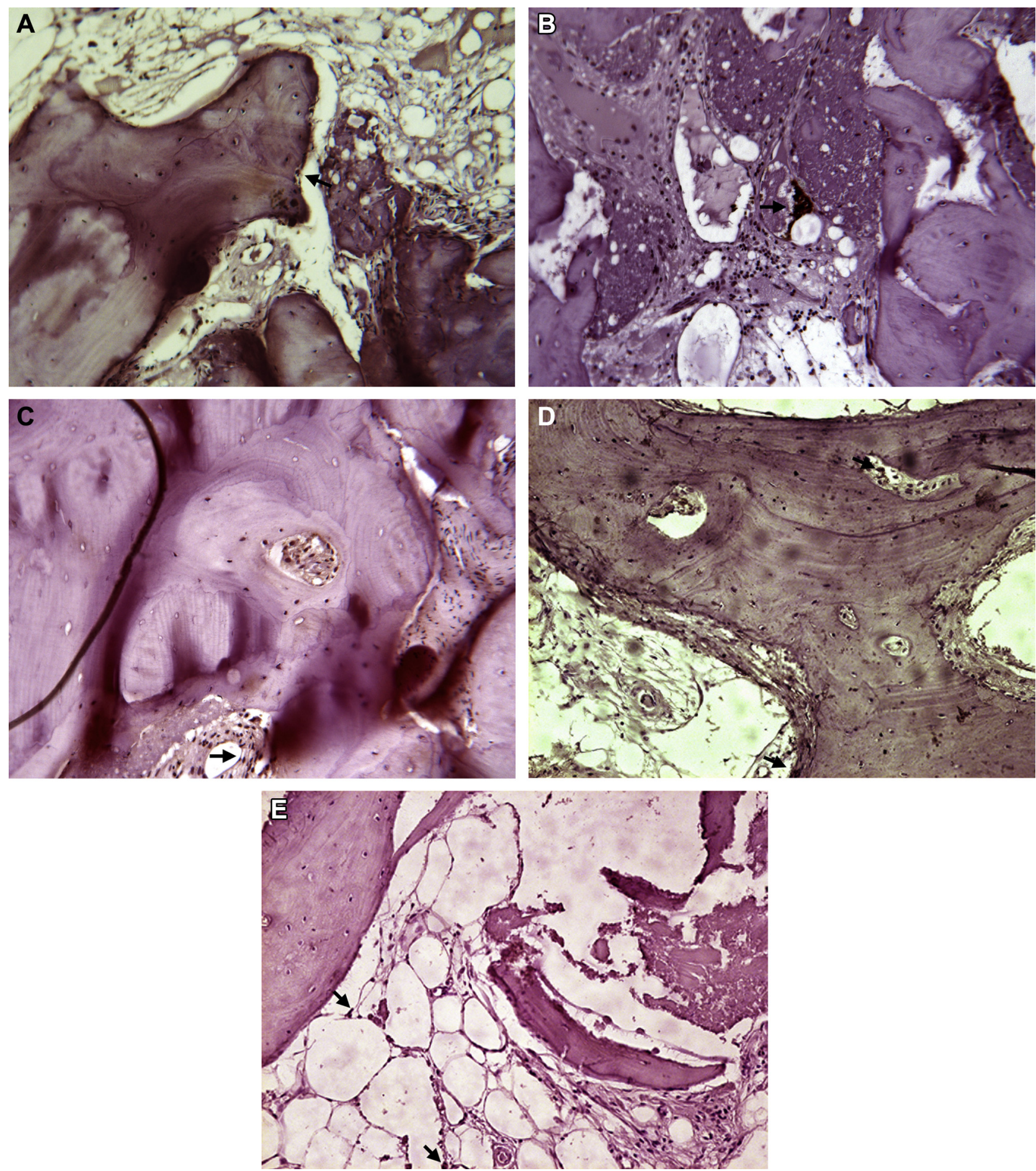

FIGURE 9. Histologic section showing positive immuno-labeling for runt-related transcription factor 2 (arrow) in $A$, group 1, $B$, group $2, C$, group 3, $D$, group 4, and $E$, group 5 (Harris hematoxylin stain; magnification, $\times 25$ ).

Bonardi et al. Chronos Versus Bio-OSS in Human Maxillary Sinuses. J Oral Maxillofac Surg 2018.

5 months of bone healing and a smaller percentage of new bone formed. The histologic feature exhibited areas of bone in contact with the biomaterial particles, no inflammatory cells, and no foreign body reaction. In the present study, the outcomes were similar for groups 4 and 5, with a notable amount of Bio-Oss particles remaining compared with the other groups evaluated.

Martinez et $a^{21}$ evaluated bone formation after maxillary sinus bone augmentation using Bio-Oss and 

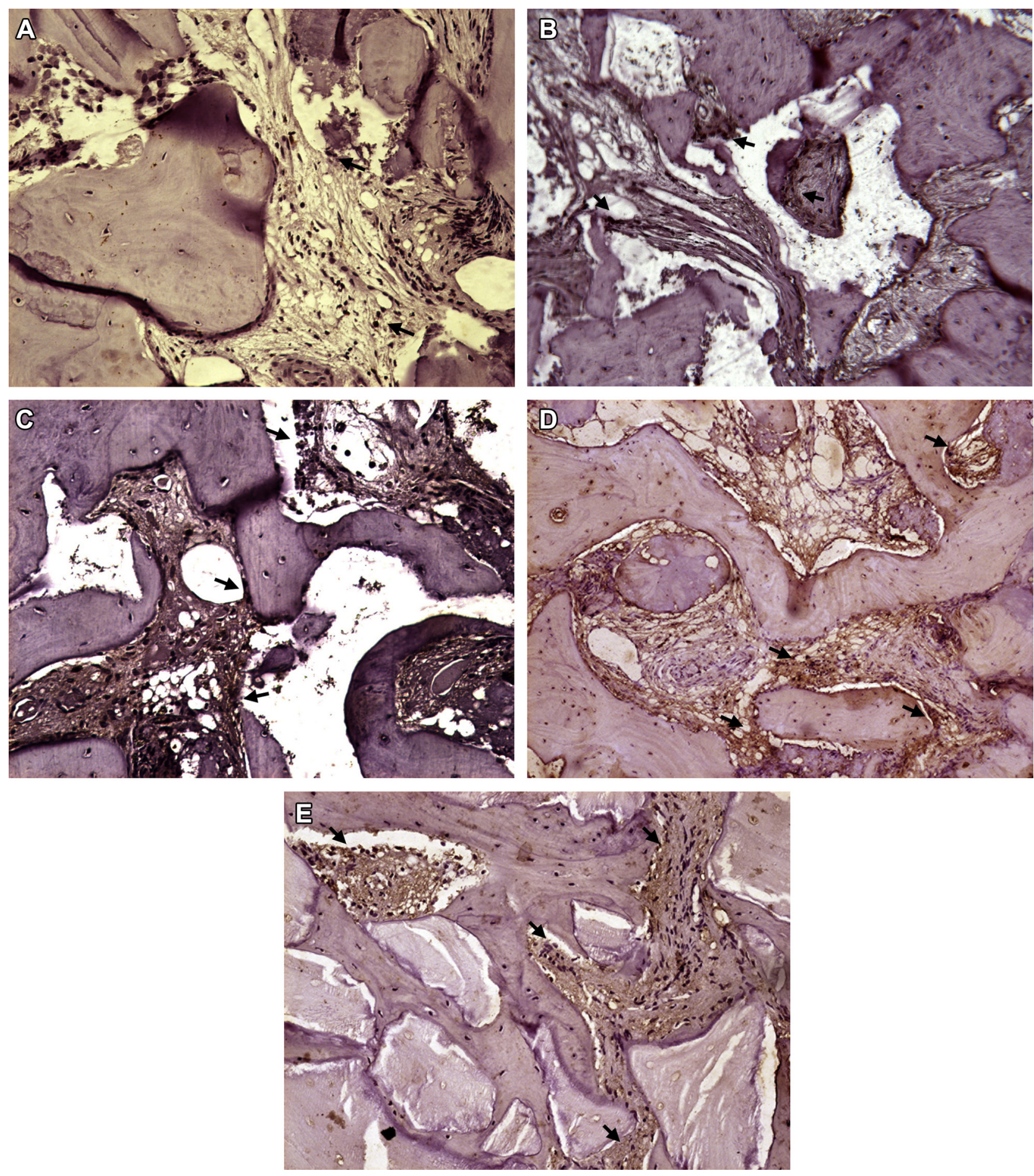

FIGURE 10. Histologic section showing positive immuno-labeling for vascular endothelial growth factor (arrow) in $A$, group $1, B$, group $2, C$, group 3, D, group 4, and $E$, group 5 (Harris hematoxylin stain; magnification, $\times 25$ ).

Bonardi et al. Chronos Versus Bio-OSS in Human Maxillary Sinuses. J Oral Maxillofac Surg 2018.

$\beta$-TCP. In their study, the amount of new bone formation in the maxillary sinuses grafted with $\beta$-TCP was larger and there were fewer biomaterial particles remaining. These results corroborate those of the present study; however, when autogenous bone graft was added, the mixture of $\beta$-TCP and autogenous bone in a 1:1 ratio showed more bone formation compared with the composite graft with Bio-Oss.

With the exception of group 3, the other groups evaluated in this study exhibited mature bone 

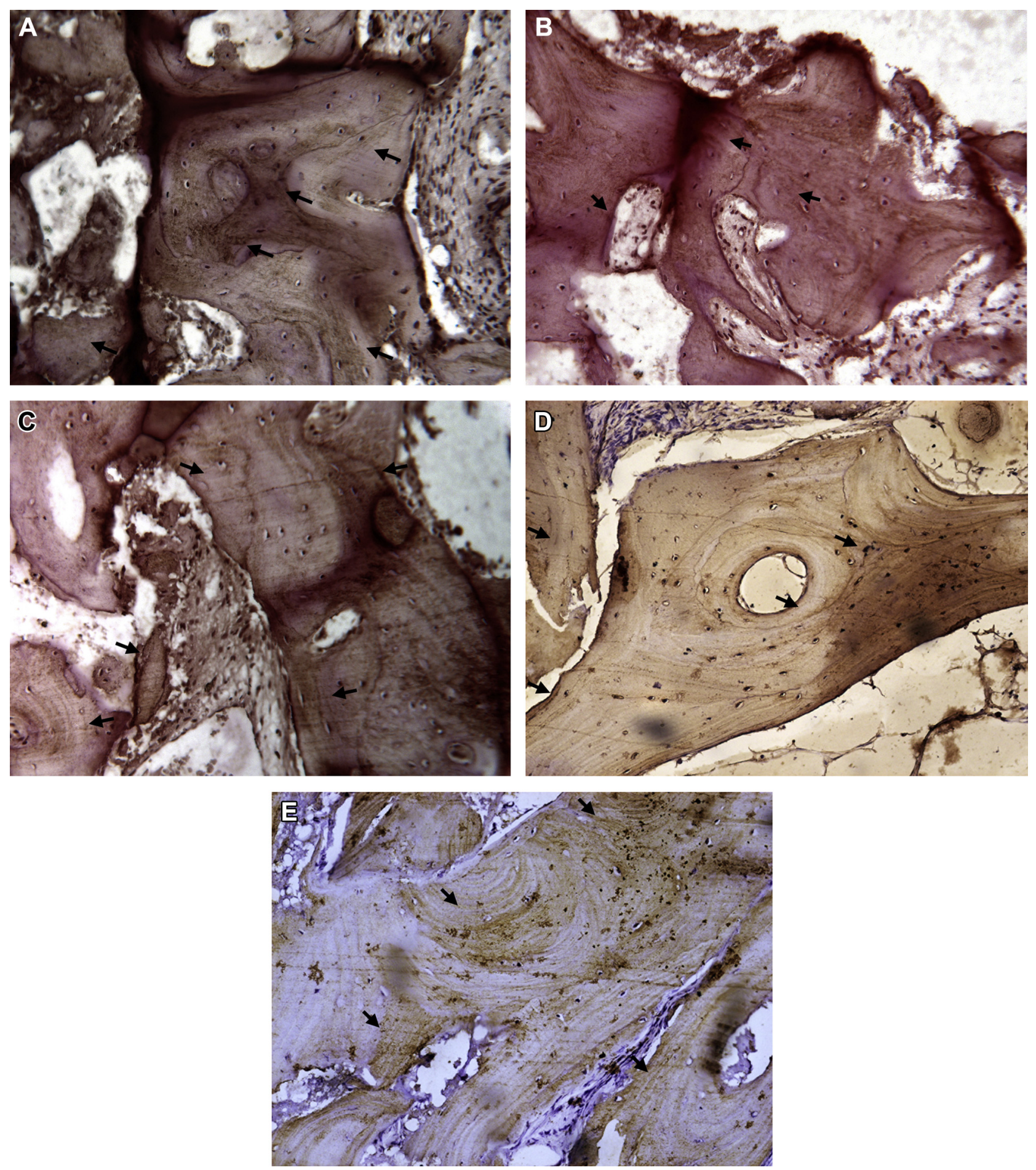

FIGURE 11. Histologic section showing positive immuno-labeling for osteocalcin (arrow) in $A$, group 1, B, group 2, C, group $3, D$, group 4 , and $E$, group 5 (Harris hematoxylin stain; magnification, $\times 25$ ).

Bonardi et al. Chronos Versus Bio-OSS in Human Maxillary Sinuses. J Oral Maxillofac Surg 2018.

formation, areas with lamellar formation, and low (score, 1) immuno-labeling for Runx 2 , indicating little pre-osteoblastic activity. Despite this, osteocalcin showed intense (score, 3) staining, indicating a high degree of bone calcification. The immunostaining for
VEGF presented results from moderate (score, 2) to intense (score, 3) for most groups, except for group 5 , which had a low score of 1 , indicating the presence of vascular proliferation. Group 3 presented a delayed maturation stage, with few osteocytes in the 
Table 4. IMMUNO-LABELING SCORES FOR RUNX2, VEGF, AND OSTEOCALCIN

$\begin{array}{llll}\text { Groups } & \text { Runx } 2 & \text { VEGF } & \text { Osteocalcin }\end{array}$

\begin{tabular}{llll}
1 & 1 & 2 & 3 \\
2 & 1 & 2 & 3 \\
3 & 2 & 3 & 3 \\
4 & 1 & 3 & 3 \\
5 & 1 & 1 & 3 \\
\hline
\end{tabular}

Abbreviations: Runx2, runt-related transcription factor 2; VEGF, vascular endothelial growth factor.

Bonardi et al. Chronos Versus Bio-OSS in Human Maxillary Sinuses. J Oral Maxillofac Surg 2018.

extracellular matrix and moderate (score, 2) immunolabeling for Runx 2, showing a higher level of preosteoblastic activities.

The use of ChronOs combined with autogenous bone graft in a 1:1 ratio showed similar new bone formation as autogenous bone graft alone, indicating that the fast resorption and osteoconduction of ChronOS make this combination a reliable bone substitute. The group grafted with Bio-Oss added to autogenous bone graft in a 1:1 ratio showed slow resorption of graft particles with discrepant outcomes compared with autogenous bone graft alone. Therefore, these results suggest that the low rates of new bone formation in the 2 groups were due to the presence of remaining Bio-Oss particles. Nonetheless, these bone substitutes have high rates of success with dental implants (range, 98.2 to $100 \%)^{37,38}$

In conclusion, ChronOS combined with autogenous bone graft in a 1:1 ratio presented behavior similar to that of autogenous bone graft alone. However, the groups with Bio-Oss had histomorphometric and immuno-labeling scores for the proteins evaluated, indicating maturation of the grafted bone, thus allowing the placement of dental implants.

\section{References}

1. Kassebaum NJ, Bernabé E, Dahiya M, et al: Global burden of severe tooth loss: A systematic review and meta-analysis. J Dent Res 93(7 Suppl):20S, 2014

2. Wagner F, Dvorak G, Nemec S, et al: A principal components analysis: How pneumatization and edentulism contribute to maxillary atrophy. Oral Dis 23:55, 2017

3. Sharan A, Madjar D: Maxillary sinus pneumatization following extractions: A radiographic study. Int J Oral Implants Maxillofac $23: 48,2008$

4. Misch CE: Contemporary Implant Dentistry (ed 3). St Louis, MO, Elsevier, 2008, pp 389-402

5. Boyne PJ, James RA: Grafting of the maxillary sinus floor with autogenous marrow and bone. J Oral Surg 38:613, 1980

6. Misch CE: Maxillary sinus augmentation for endosteal implants: Organized alternative treatment plans. Int J Oral Maxillofac Implants 4:49, 1987
7. Wood RM, Moore DL: Grafting of the maxillary sinus with intraorally harvested autogenous bone prior to implant placement. Int J Oral Maxillofac Implants 3:209, 1988

8. Hench LL: Biomaterials: A forecast for the future. Biomaterials 19:1419, 1998

9. Sbordone L, Toti P, Menchini-Fabris GB, et al: Volume changes of autogenous bone grafts after alveolar ridge augmentation of atrophic maxillae and mandibles. Int J Oral Maxillofac Surg 38:1059, 2009

10. Moy PK, Lundgren S, Holmes RE: Maxillary sinus augmentation-Histomorphometric analysis of graft materials for maxillary sinus floor augmentation. J Oral Maxillofac Surg 51:857, 1993

11. Yildirim M, Spiekermann H, Handt S, Edelhoff D: Maxillary sinus augmentation with the xenograft Bio-Oss and autogenous intraoral bone for qualitative improvement of the implant site: A histologic and histomorphometric clinical study in humans. Int J Oral Maxillofac Implants 16:23, 2001

12. Szabo G, Huys L, Coulthard P, et al: A prospective multicenter randomized clinical trial of autogenous bone versus betatricalcium phosphate graft alone for bilateral sinus elevation: Histologic and histomorphometric evaluation. Int J Oral Maxillofac Implants 20:371, 2005

13. Lu J, Descamps M, Dejou J, et al: The biodegradation mechanism of calcium phosphate biomaterials in bone. J Biomed Mater Res 63:408, 2002

14. Ghosh R, Sarkar R: Synthesis and characterization of sintered beta-tricalcium phosphate: A comparative study on the effect of preparation route. Mater Sci Eng C Mater Biol Appl 67:345, 2016

15. Artzi Z, Weinreb M, Givol N, et al: Biomaterial resorption rate and healing site morphology of inorganic bovine bone and beta-tricalcium phosphate in the canine: A 24-month longitudinal histologic study and morphometric analysis. Int J Oral Maxillofac Implants 19:357, 2004

16. Okada T, Kanai T, Tachikawa N, et al: Long-term radiographic assessment of maxillary sinus floor augmentation using betatricalcium phosphate: Analysis by cone-beam computed tomography. Int J Implant Dent 2:8, 2016

17. Gorla LF, Spin-Neto R, Boos FB, et al: Use of autogenous bone and beta-tricalcium phosphate in maxillary sinus lifting: A prospective, randomized, volumetric computed tomography study. Int J Oral Maxillofac Surg 44:1486, 2015

18. Peters F, Reif D: Functional materials for bone regeneration from $\beta$-tricalcium phosphate. Materwiss Werksttech 35:203, 2004

19. Weibrich G, Trettin R, Gnoth SH, et al: [Determining the size of the specific surface of bone substitutes with gas adsorption]. Mund Kiefer Gesichtschir 4:148, 2000 (in German)

20. Traini T, Degidi M, Sammons R, et al: Histologic and elemental microanalytical study of anorganic bovine bone substitution following sinus floor augmentation in humans. J Periodontol 79:1232, 2008

21. Martinez A, Franco J, Saiz E, Guitian F: Maxillary sinus floor augmentation on humans: Packing simulations and 8 months histomorphometric comparative study of anorganic bone matrix and $\beta$-tricalcium phosphate particles as grafting materials. Mater Sci Eng C Mater Biol Appl 30:763, 2010

22. Cohen MM: Perspectives on RUNX genes: An update. Am J Med Genet A 149A:2629, 2009

23. Maruyama Z, Yoshida CA, Furuichi T, et al: Runx2 determines bone maturity and turnover rate in postnatal bone development and is involved in bone loss in estrogen deficiency. Dev Dyn 236: 1876,2007

24. Kempen DH, Lu L, Heijink A, et al: Effect of local sequential VEGF and BMP-2 delivery on ectopic and orthotopic bone regeneration. Biomaterials 14:2816, 2009

25. Kwon TG, Zhao X, Yang Q, et al: Physical and functional interactions between Runx 2 and HIF- $1 \alpha$ induce vascular endothelial growth factor gene expression. J Cell Biochem 12:3582, 2011

26. De Souza Nunes LS, De Oliveira RV, Holgado LA, et al: Immunoexpression of Cbfa-1/Runx 2 and VEGF in sinus lift procedures using bone substitutes in rabbits. Clin Oral Implants Res 21:584, 2010 
27. Degidi M, Artese L, Rubini C, et al: Microvessel density in sinus augmentation procedures using anorganic bovine bone and autologous bone: 3 Month results. Implant Dent 16:317, 2007

28. Mayr-Wohlfart U, Waltenberger J, Hausser H, et al: Vascular endothelial growth factor stimulates chemotactic migration of primary human osteoblasts. Bone 30:472, 2002

29. Street J, Bao M, deGuzman L, et al: Vascular endothelial growth factor stimulates bone repair by promoting angiogenesis and bone turnover. Proc Nati Acad Sci U S A 99:9656, 2002

30. Degidi M, Artese L, Rubini C, et al: Microvessel density and vascular endothelial growth factor expression in sinus augmentation using Bio-Oss. Oral Dis 12:469, 2006

31. Hughes SS, Hicks DG, Okeefe RJ, et al: Shared phenotypicexpression of osteoblasts and chondrocytes in fracture callus J Bone Miner Res 10:533, 1995

32. Schroeder TM, Westendorf JJ: Histone deacetylase inhibitors promote osteoblast maturation. J Bone Miner Res 20:2254, 2005

33. Pereira RS, Gorla LF, Boos FB, et al: Use of autogenous bone and beta-tricalcium phosphate in maxillary sinus lifting: Histomorphometric study and immunohistochemical assessment of RUNX2 and VEGF. Int J Oral Maxillofac Surg 46:503, 2017
34. Dos Santos Pereira R, Boos FB, Gorla LF, et al: Maxillary sinus elevation surgery with ChronOS and autogenous bone graft: Analysis of histometric and volumetric changes. Int J Periodontics Restorative Dent 36:885, 2016

35. Jensen T, Schou S, Stavropoulos A, et al: Maxillary sinus floor augmentation with Bio-Oss or Bio-Oss mixed with autogenous bone as graft: A systematic review. Clin Oral Implants Res 23: 263,2012

36. Shirmohammadi A, Roshangar L, Chitsazi MT, et al: Comparative study on the efficacy of anorganic bovine bone (Bio-Oss) and nanocrystalline hydroxyapatite (Ostim) in maxillary sinus floor augmentation. Int Sch Res Notices 2014:967091, 2014

37. Galindo-Moreno P, Padial-Molina M, Fernández-Barbero JE, et al: Optimal microvessel density from composite graft of autogenous maxillary cortical bone and anorganic bovine bone in sinus augmentation: influence of clinical variables. Clin Implant Oral Res 21:221, 2010

38. Dinato TR, Grossi ML, Teixeira ER, et al: Marginal bone loss in implants placed in the maxillary sinus grafted with anorganic bovine bone: A prospective clinical and radiographic study. J Periodontol 87:880, 2016 